\title{
PENINGKATAN RANCANGAN WAYFINDING (MENEMUKAN JALAN) UNTUK SEKOLAH PENYANDANG DISABILITAS VISUAL DI SURABAYA DAN PELUANG PENGEMBANGANNYA UNTUK BANGUNAN PUBLIK LAINNYA
}

\author{
Tutus Setiawan $^{1}$, Gunawan Tanuwidjaja ${ }^{2 \& 3}$, Mohamad Ali Muhaidhori ${ }^{1}$ \\ 1. SMPLB-A Yayasan Pendidikan Anak Buta, \\ Jalan Gebang Putih No. 5 Surabaya \\ 2. Program Studi Arsitektur, Universitas Kristen Petra, \\ Jalan Siwalankerto No. 121-131 Surabaya \\ 3. School of Design, Creative Industry Faculty, Queensland University of Technology, \\ 2 George Street, Brisbane, Australia \\ Email: ${ }^{1}$ tutusypab1980@gmail.com, ${ }^{2}$ gunte@petra.ac.id
}

\begin{abstract}
Abstrak
Sekolah Menengah Pendidikan Luar Biasa A Yayasan Anak Anak Buta (SMPLB-AYPAB) di Surabaya adalah lembaga yang didedikasikan untuk mengajar siswa tuna netra. Sayangnya, sekolah ini kurang dapat diakses oleh orang buta karena dirancang untuk sekolah pertanian dengan jejak kaki bangunan yang tersebar pada tahun 1970-an. Tinjauan pustaka dan evaluasi aksesibilitas menyimpulkan bahwa selain peningkatan arsitektur, model arsitektur kecil diperlukan untuk mengajar siswa agar dapat melakukan orientasi dan mobilitas. Model ini harus dapat diakses oleh siswa tuna netra, tuna netra total dan low vision, dengan berbagai informasi seperti suara, braille, warna kontras, dan tanda sentuhan. Model arsitektur ini dirancang dalam kolaborasi guru YPAB, Program Arsitektur, Program Elektro Universitas Kristen Petra dan Prototipe Studio. Model ini dibuat dengan pemotongan laser dan dilengkapi dengan sirkuit elektronik untuk instruksi penuntun suara bagi siswa tuna netra. Model ini ditemukan meningkatkan siswa tuna netra untuk mempraktikkan orientasi dan mobilitas di sekolah. Penelitian lebih lanjut mengejar peningkatan pencarian jalan umum untuk orang-orang buta seperti yang dijelaskan dalam the State Library of Queensland (SLQ).
\end{abstract}

Kata kunci: aksesibilitas, sirkuit terintegrasi, model arsitektur, sirkuit elektronik, sistem suara.

\begin{abstract}
Title: Wayfinding Design Improvement for the Blind School in Surabaya and Development Opportunities for Other Public Buildings

Yayasan Pendidikan Anak Buta (Blind Children Education Foundation or YPAB) Special Junior High School in Surabaya is a dedicated institution for teaching blind students. Unfortunately, the school is found less accessible for the blind because it was designed for the farming school with spread buildings' footprints in the 1970s. A literature review and accessibility evaluation conclude that besides architecture improvement, a small architectural model is needed to teach the students to be able to conduct orientation and mobility. The model should be accessible to blind students, total blind and low vision, with various information such as voice, braille, contrasting colour, and tactile marking. This architecture model is designed in collaboration of YPAB teachers, Architecture Program Study, Electrical Program Study of Petra Christian University and Prototype Studio. The model is created with laser cutting and equipped with electronic circuits for the voice of wayfinding instructions for blind students. The model is found improving the blind students to practice orientation and mobility in the school. Further research pursues improving public building wayfinding for the blind persons as described in the State Library of Queensland (SLQ).
\end{abstract}

Keywords: accessibility, integrated circuit, architecture model, electronics circuit, sound system. 


\section{Pendahuluan}

Penyandang Disabilitas Visual (PDV) perlu petunjuk cara mencari yang berbeda untuk dapat menggunakan fasilitas publik, yaitu sekolah, universitas, perpustakaan dan museum. Papan tanda braille dan ubin pemandu diperlukan untuk mencari jalan PDV. Selain itu, Orientasi dan Mobilitas (O\&M) sangat penting bagi PDV karena membantu mereka memahami kondisi lingkungan dan menemukan petunjuk. Di Sekolah Menengah Pertama Luar Biasa Tipe A Yayasan Pendidikan Anak Buta (SMPLB-A YPAB), proses O\&M dilakukan untuk siswa yang baru masuk selama satu bulan untuk memfasilitasi keterampilan sirkulasi mereka. Sayangnya, tidak semua penyandang disabilitas bisa menghafal rute dan isyarat tanpa bantuan. Oleh karena itu, model arsitektur-dan-audio-deskriptif terintegrasi diusulkan oleh Tutus Setiawan untuk sekolah. Penelitian ini selanjutnya dilakukan dalam kolaborasi antara Sekolah Menengah YPAB, Program Studi Elektro Universitas Kristen Petra (UKP), Program Studi Arsitektur UKP, Maketor Arsitektur Prototype Studio dan Green Impact Studio (sponsor parsial).

Sekolah Menengah YPAB awalnya dirancang untuk Sekolah Menengah Kejuruan untuk Pertanian dengan tata letak bangunan yang berjauhan. Oleh karena itu, ada banyak kolam, ruang hijau, serta gudang pertanian. Konversi Sekolah Menengah untuk melayani PDV dilakukan dalam waktu yang lama dan dengan intervensi arsitektur minimal karena kesulitan keuangan. Oleh karena itu, pelatihan O\&M sangat penting untuk meningkatkan keterampilan siswa yang buta.
Pengamatan PDV di YPAB School telah dilakukan sejak 2012, oleh Tim Desain Program Studi Arsitektur dengan bantuan dari tim pengajar YPAB mengikuti Herssens (2011). PDV dikategorikan menjadi buta total dan low vision. Proses O\&M dapat difasilitasi dengan model arsitektur dengan memasukkan tanda braille, warna yang kontras, tekstur yang berbeda dari model arsitektur (diferensiasi antara sirkulasi, lanskap hijau dan bangunan), serta rekaman audio (terdiri dari instruksi O\&M untuk PDV). Perangkat bantuan O\&M dirancang menggunakan proses desain inklusif. Karena itu, ini lebih panjang dari proses desain-dan-bangun konvensional. Namun demikian, kegunaan model terintegrasi dapat dioptimalkan.

Wayfinding didefinisikan sebagai kemampuan untuk menemukan jalur ke lokasi. Sementara itu, orientasi spasial dijelaskan sebagai kemampuan individu untuk memahami ruang di sekitarnya dan merendahkan dirinya (Passini, 1984). Persepsi dan kognisi ternyata banyak terkait dengan keterampilan mencari arah dan orientasi (Boulding, 1956; Lynch, 1960). Boulding (1956) berpendapat bahwa untuk memahami tindakan seseorang, kita harus memahami apa yang mereka pahami, mereka tahu dan mereka percayai karena image (gambar yang tertanam) dalam pikiran manusia dapat mempengaruhi kehidupan mereka. Oleh karena itu, persepsi atau kognisi ini perlu dipelajari untuk memahami proses menemukan jalan dan berorientasi pada seseorang.

Peta kognitif spasial ditemukan sangat penting oleh Lynch (1960). Citra lingkungan yang jelas akan membantu seseorang berfungsi secara efisien, terutama dalam menemukan cara dan berorientasi. Sehingga dapat 
disimpulkan jika seseorang dapat menemukan jalan, maka ia akan memiliki gambaran yang jelas tentang lingkungannya (baik secara verbal maupun citra). Lynch menemukan beberapa elemen yang dianggap oleh individu sebagai penanda lingkungan mereka. Lynch berpendapat bahwa aksesibilitas visual dan dampak visual adalah kriteria penting untuk tempat yang mudah diingat dan mudah dibaca. Sayangnya, sedikit dipahami bagaimana PDV mempersepsikan informasi spasial dengan model arsitektur. Oleh karena itu, model terintegrasi ini diusulkan. Paper ini telah dipaparkan parsial dalam The $2^{\text {nd }}$ International Conference on Disability and Diversity in Asia, Fakultas Hukum Universitas Brawijaya pada 24-25 September 2019.

\section{Tinjauan Literatur}

Secara umum, keterampilan akademik PDV dipengaruhi oleh tidak adanya teknologi adaptif untuk pendidikan inklusif. Reed \& Curtis (2012) mempelajari pengalaman siswa dengan disabilitas visual dalam pendidikan tinggi Kanada. Wawancara mendalam responden menunjukkan kendala waktu bagi penyandang disabilitas untuk lulus lebih cepat (atau dengan 1,5 tahun akademik tambahan). Hambatan tersebut disebabkan oleh persyaratan membaca yang berat, karya kelompok dan banyak persyaratan akademis lainnya. Selain itu, PDV juga menemukan hambatan dalam studi akademik di sekolah menengah Kanada (Reed dan Curtis, 2012; Klinkosz, Sekowski \& Brambring, 2006).

Di sisi lain, teknologi informasi adaptif dapat dipromosikan untuk meningkatkan keterampilan akademik para penyandang disabilitas (Reed \& Curtis, 2012). Oleh karena itu, alat adaptif untuk desain wayfinding juga diperlukan untuk meningkatkan pencarian arah PDV.

Wright, Harris \& Sticken (2010) berpendapat bahwa kinerja Orientasi dan Mobilitas PDV ditingkatkan oleh peta dan model taktil dalam empat praeksperimental dan tiga eksperimental yang dihasilkan dari literatur yang diterbitkan antara tahun 1965 dan 2008. Kurikulum inti diperluas untuk siswa dengan gangguan visual (ECC) menggambarkan keterampilan Orientasi dan Mobilitas (O\&M) sebagai salah satu dari sembilan keterampilan yang dibutuhkan oleh PDV. Keahlian O\&M pada dasarnya membutuhkan bantuan peta dan model taktil untuk membuat peta kognitif dan menciptakan kesiapan dalam PDV.

Budd \& La Grow (2000) dan Franks (1974) menyoroti pentingnya instruksi formal dalam O\&M dengan bantuan peta atau model. Siswa dapat belajar O\&M lebih cepat dengan instruksi formal seperti yang diperkenalkan oleh Frank dalam kurikulum O\&M untuk remaja. Peningkatan keterampilan O\&M pada setiap siswa konsisten dan tampak signifikan. Studi menunjukkan bahwa pendidikan formal dalam konsep O\&M menggunakan peta dan model taktil mungkin bermanfaat.

Penggunaan peta taktil yang berhasil telah dievaluasi oleh Berla (1973) yang melibatkan tugas akuisisi, kelancaran, pemeliharaan dan generalisasi dalam proses O\&M. Wolery, Ault \& Doyle (1992) telah menemukan pembelajaran bahwa kemampuan awal akan memengaruhi proses O\&M. Fase kelancaran, pemeliharaan, transfer keterampilan ke situasi tidak dibahas. Sementara itu, Ungar, Blades, Spencer \& Morsley (1994) menemukan kecepatan peserta dalam menemukan obyek pada peta dan memperkirakan arah pada proses mempengaruhi kinerja wayfinding (menemukan jalan). 
Oleh karena itu, peta taktil sederhana sangat penting.

Wright, Harris \& Sticken (2010) menemukan bahwa para peserta dapat melakukan tugas mencari jalan utama di kelas, tetapi tidak dapat melaksanakan keterampilan O\&M di lingkungan alami. Jika peserta diberi peta yang menyertakan lokasi landmark penting (halte dan persimpangan), anak-anak dengan Disabilitas Visual dapat melakukan pencarian jalan dengan peta dan model.

Altay \& Demirkan (2014) berpendapat pentingnya pemodelan empatik dalam mengembangkan praktik Desain Inklusif dengan siswa. Desainer harus mempertimbangkan spektrum pengguna yang lebih luas dalam desain mereka. Desain Inklusif (ID) sangat penting untuk diajarkan dalam pendidikan desain. Altay \& Demirkan (2014) berfokus pada tujuan pendidikan dan kegiatan pembelajaran terkait ID. Pemodelan empatik meningkatkan keterlibatan siswa dengan kebutuhan para penyandang disabilitas. Pemodelan melibatkan simulasi sebagai penyandang disabilitas dalam lingkungan kampus. Karena itu, proses pembuatan model terintegrasi yang lebih inklusif sangat penting.

Heylighen \& Herssens (2014) berpendapat pentingnya pengetahuan bagi perancang kota dan arsitek tentang pengetahuan tentang PDV untuk menciptakan lingkungan perkotaan yang lebih mudah diakses oleh PDV. Kualitas visual yang rasional sebagian besar disukai oleh para perancang untuk mempercantik kota-kota, di sisi lain, banyak penyandang disabilitas hidup dalam bahaya di daerah tersebut. PDV harus dilibatkan sebagai ahli yang membantu para arsitek dan perancang lainnya untuk menciptakan tempat-tempat ramah yang lebih mudah diakses dan mencari arah.

\section{Metode Penelitian}

Peningkatan desain wayfinding (menemukan jalan) untuk siswa Disabilitas Visual di Sekolah YPAB diusulkan untuk meningkatkan siswa Sekolah Menengah YPAB untuk dapat mengarahkan diri mereka sendiri dan beredar di sekolah. Program ini dilakukan selama 3 bulan. Model arsitektur-dan-audio-deskriptif terintegrasi disusun dimulai dengan analisis pemrograman sekolah dan kebutuhan sirkulasi. Instruksi O\&M direkam dan dikonversi ke format suara MP3 (Motion Picture Experts Group Layer-3). Selanjutnya, tata letak sekolah digambar ulang dengan perangkat lunak berbasis vektor (AutoCAD) dan diterjemahkan ke dalam model tiga dimensi (3D) oleh laser cutter (pemotong laser) dan perakitan manual oleh Prototype Studio. Metode printer 3D telah dipertimbangkan tetapi ditemukan mustahil karena terlalu mahal. Sirkuit listrik dirancang oleh dosen dan mahasiswa dari Program Studi Elektro. Kemudian diuji untuk blok model tertentu sebelum seluruh blok model dilengkapi dengan sirkuit yang lebih kompleks. Model terintegrasi kemudian diselesaikan oleh Prototype Studio dengan bantuan dari beberapa siswa UKP yang melakukan penjangkauan masyarakat. Model terintegrasi diuji oleh beberapa siswa YPAB dan terbukti bermanfaat untuk pelatihan O\&M.

Tahapan kegiatan ini dapat ditentukan dalam tahapan berikut:

1. Diskusi awal antara Program Studi Arsitektur UKP dan Bp. Tutus Setiawan 
2. Diskusi dengan Program Studi Elektro UKP

3. Diskusi dengan Prototype Studio

4. Persiapan rangkaian listrik dari Arduino, modul Mp3 berbasis pada chip VS 1XXX, Modul SD, LCD karakter 4x20, amplifier kecil, dan 2 speaker

5. Persiapan model arsitektur

6. Merakit sirkuit listrik dalam model arsitektur

7. Perekaman suara untuk model arsitektur bagi Disabilitas Visual

8. Integrasi model dan sirkuit elektronik

\section{Hasil dan Diskusi}

Model arsitektur-dan-audio-deskriptif terintegrasi sangat berguna untuk membantu O\&M PDV di SMPLB-A YPAB. Beberapa temuan ditemukan dalam proses aksi penelitian. Rentang jangkauan tangan siswa membatasi skala model terintegrasi. Skala model dibuat hingga 1:150 karena mempertimbangkan ukuran total model. Ukuran total model adalah 85 $\mathrm{cm} \times 85 \mathrm{~cm}$.

Kedua, instruksi O\&M untuk pencarian arah dijelaskan menggunakan sejumlah langkah. Panjang langkah PDV bervariasi antara siswa berusia 12 tahun dan 18 tahun. Oleh karena itu, pengukuran jarak jejak siswa YPAB harus dihitung untuk mengurangi perhitungan cara pencarian yang salah. Petunjuk pencarian jalan lain juga harus ditambahkan seperti papan tanda braille dan indikator permukaan tanah sentuhan atau paving sentuhan, pagar atau fitur lain untuk meningkatkan efektivitas siswa sekolah YPAB.

Ketiga, komponen penjangkauan komunitas siswa UKP ditemukan positif dalam meningkatkan empati dan kesadaran akan pentingnya Desain Inklusif dalam proses profesional.
Jurnal yang dibuat oleh siswa menunjukkan perubahan perspektif setelah program. Sementara itu, para guru dan siswa YPAB dengan Disabilitas Visual merasakan dampak positif dari model terintegrasi dan program O\&M yang baru.

Kegiatan ini akan diperluas untuk menciptakan model arsitektur-danaudio-deskriptif terintegrasi untuk penyandang disabilitas di fasilitas pendidikan publik di Surabaya. Model pencarian jalan untuk penyandang disabilitas diamati di State Library of Queensland (SLQ). Perpustakaan menyediakan model taktil-Braille terintegrasi untuk mencari jalan PDV. Model ini diusulkan pada tahun 1984 dan diperbarui pada tahun 2004 dalam hal peningkatan akses gedung. Model ini adalah contoh yang sangat baik tentang bagaimana PDV difasilitasi dalam mengakses gedung-gedung publik. Sayangnya, di Indonesia tidak ada model yang dapat diakses untuk PDV dan menyebabkan proses O\&M lebih sulit untuk dilaksanakan. Oleh karena itu eksplorasi dilakukan untuk membuat produk untuk penggunaan komersial di perpustakaan umum atau pusat perbelanjaan.

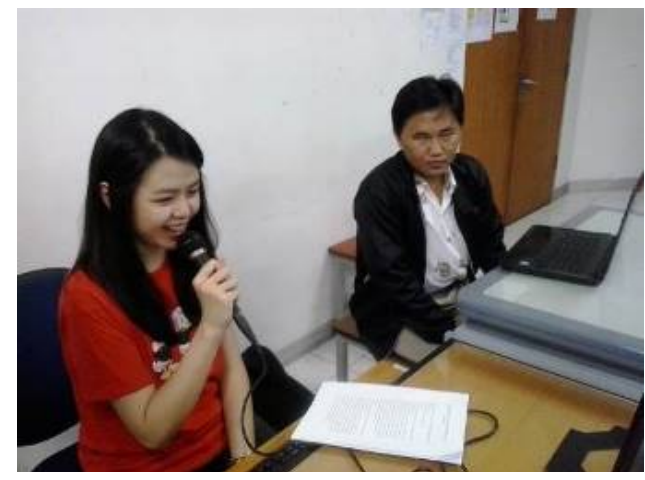

Gambar 1. Perekaman suara untuk menciptakan model terpadu untuk SMPB-A YPAB

Sumber: Dokumentasi Setiawan, dkk., 2019 


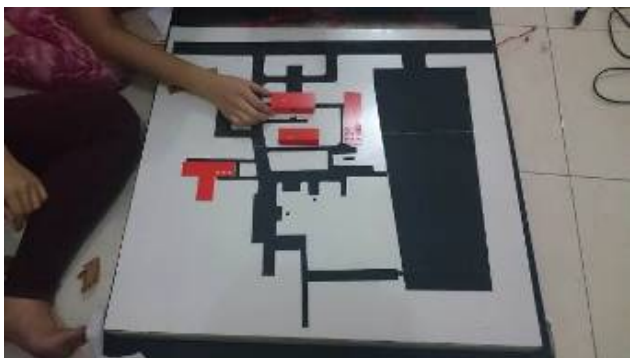

Gambar 2. Tata letak untuk model terpadu untuk SMPB-A YPAB

Sumber: Dokumentasi Setiawan, dkk., 2019

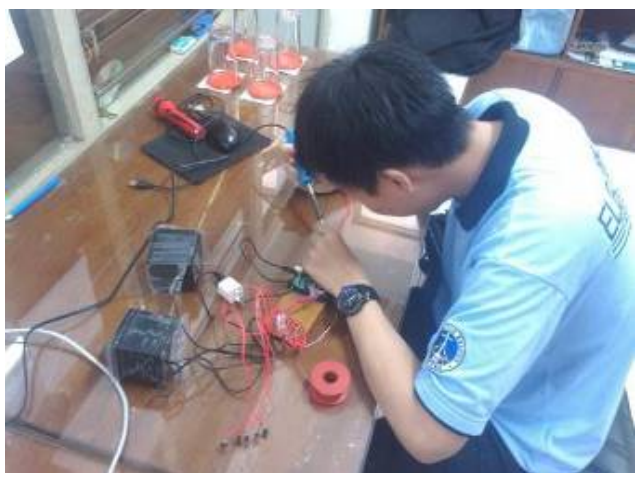

Gambar 3. Perakitan sirkuti untuk model terpadu untuk SMPB-A YPAB

Sumber: Dokumentasi Setiawan, dkk., 2019

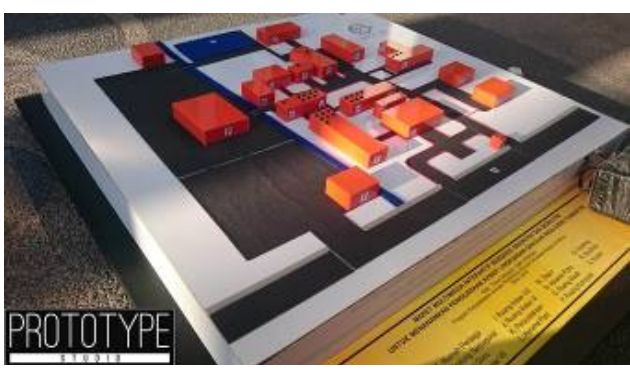

Gambar 4. Model terpadu untuk SMPB-A YPAB

Sumber: Dokumentasi Setiawan, dkk., 2019

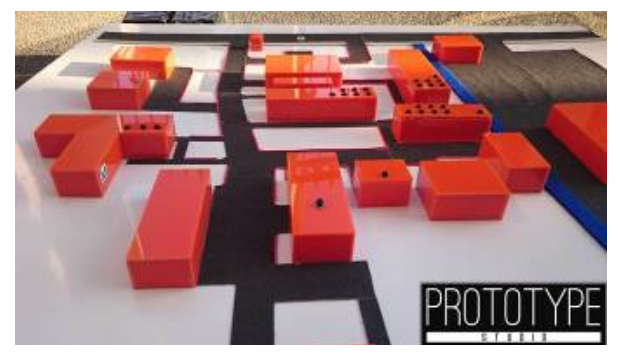

Gambar 5. Pembedaan tekstur dan warna kontras untuk memudahkan siswa menggunakan model terpadu untuk SMPBA YPAB

Sumber: Dokumentasi Setiawan, dkk., 2019

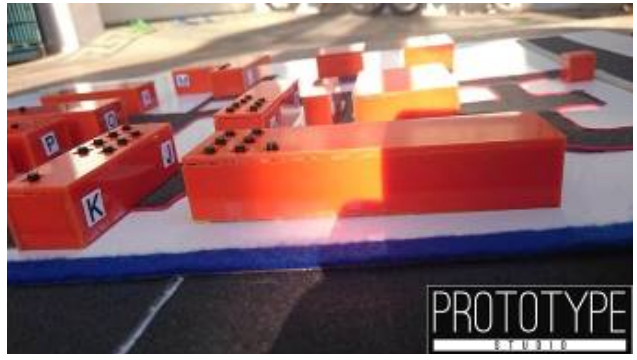

Gambar 6. Desain tombol petunjuk wayfinding pada model terpadu untuk SMPB-A YPAB

Sumber: Dokumentasi Setiawan, dkk., 2019

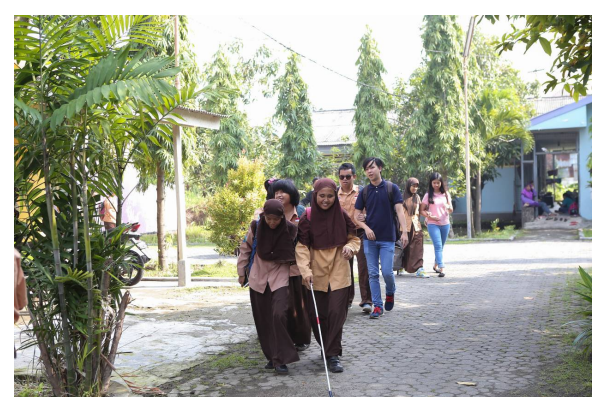

Gambar 7. Simulasi proses wayfinding dengan model terpadu untuk SMPB-A YPAB

Sumber: Dokumentasi Setiawan, dkk., 2019

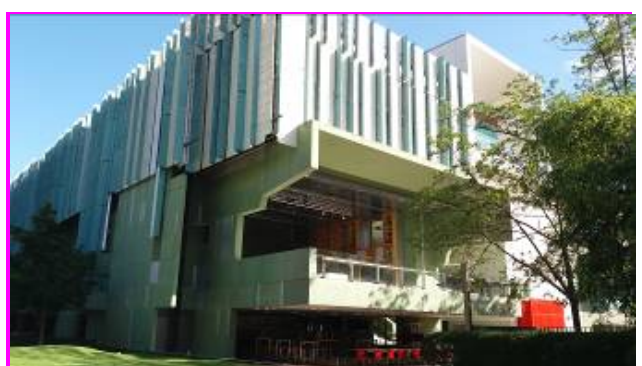

Gambar 8. Lokasi the State Library of Queensland (SLQ).

Sumber: Dokumentasi Setiawan, dkk., 2019

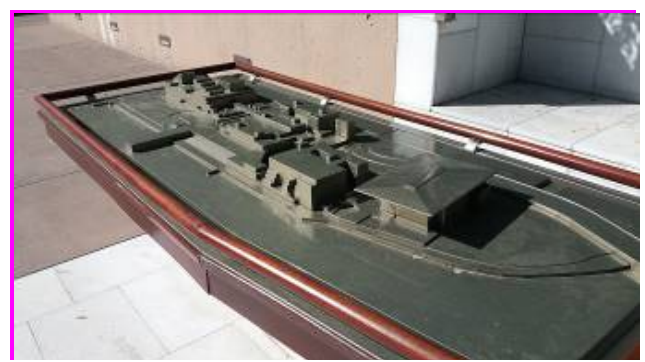

Gambar 9. Model arsitektur untuk the State Library of Queensland (SLQ).

Sumber: Dokumentasi Setiawan, dkk., 2019 


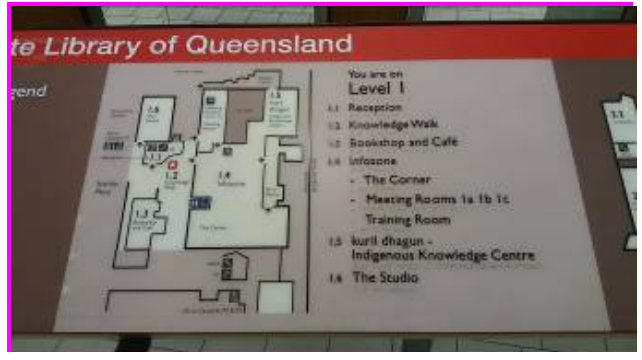

Gambar 10. Denah braille untuk the State Library of Queensland (SLQ)

Sumber: Dokumentasi Setiawan, dkk., 2019

\section{Kesimpulan}

Model terpadu ditemukan sangat membantu untuk meningkatkan Orientasi dan Mobilitas siswa SMPLBA YPAB. Di sisi lain, kami menemukan potensi replikasi model di gedung-gedung publik terutama di Indonesia. Penerapan ini akan meningkatkan kemudahan jalan bagi semua pengunjung seperti yang disajikan di the State Library of Queensland (SLQ), Brisbane, Australia. Penelitian lebih lanjut diperlukan terkait dengan penggunaan satuan meter untuk informasi jarak agar menemukan jalan dengan lebih akurat yang dijelaskan dalam instruksi suara. Keterlibatan Penyandang Disabilitas Visual dalam pembuatan model juga ditemukan sebagai kunci penting untuk kesuksesan produk inklusif dan desain lingkungan.

\section{Daftar Pustaka/ Referensi}

Altay, B. \& Demirkan, H. (2014). Inclusive design: Developing students' knowledge and attitude through empathic modelling. International Journal of Inclusive Education, 18(2), 196-217. doi: 10.1080/13603116.2013.764933

Berla, E. P. (1973). Strategies in scanning a tactual pseudomap. Education of the Visually Handicapped, 5, 8-19.
Boulding, K. E. (1956). The image: Knowledge in life and society (Vol. 47). Michigan: University of Michigan Press.

Budd, J. M. \& La Grow, S. J. (2000). Using a three-dimensional interactive model to teach environmental concepts to visually impaired children. RE:view, 32, 8394.

Franks, F. L. (1974). Introduction to map study: Teaching locational and directional referents to young blind students (Doctoral Dissertation, George Peabody College for Teachers, Nashville, TN, 1974. Unpublished).

Herssens, J. (2011). Designing architecture for more: A framework of haptic design parameters with the experience of people born blind. (Doctoral Dissertation, Hasselt University and KU Leuven, 2011).

Heylighen, A. \& Herssens, J. (2014). Designerly ways of not knowing: What designers can learn about space from people who are blind. Journal of Urban Design, 19(3), 116. doi: 10.1080/13574809.2014.890042

Klinkosz, Sekowski \& Brambring. (2006). Academic achievement and personality in university students who are visually impaired. Journal of Visual Impairment \& Blindness, November 2006, 666-675. doi: $10.1177 / 0145482 X 0610001105$

Lynch, K. (1960). The image of the city. Cambridge Mass: MIT Press.

Passini, R. (1984). Wayfinding in architecture. New York: Van Nostrand Reinhold.

Reed, M. \& Curtis, K. (2012). Experience of students with visual impairments in Canadian Higher Education. Journal of Visual Impairment \& Blindness, 106(7), 414-425. 
Ungar, S., Blades, M., Spencer, C. \& Morsley, K. (1994). Can visually impaired children use tactile maps to estimate directions? Journal of Visual Impairment \& Blindness, 88, 221-233.

Wolery, M., AuIt, M. J. \& Doyle, P. M. (1992). Teaching students with moderate to severe disabilities: Use of response prompting strategies, (pp. 11-22). White Plains, NY: Longman.

Wright, T., Harris, B. \& Sticken, E. (2010). A best-evidence synthesis of research on Orientation and Mobility involving tactile maps and models. Journal of Visual Impairment \& Blindness, 104(2), 95-106.

\section{Ucapan Terima Kasih}

Kami ingin menyampaikan penghargaan tertinggi kepada Universitas Negeri Surabaya, Yayasan Pendidikan Anak Buta (YPAB), SMPLB-A YPAB (Bapak Eko Purwanto dan Ibu Dwi Rahmawati), Program Studi Elektro UKP (Handry Khoswanto dan Murtiyanto Santoso), Prototype Studio, Green Impact Indonesia Studio (Sponsor Parsial). Kami juga ingin mengucapkan terima kasih khusus kepada Ivan Hendrayanta Susilo, Steven Kimsha, Maria Monica Rampisela, Hendy Gunawan, Dian Naftali, Parengkuan Jonathan Richard, Prema Kresna Dianthi yang telah mendukung aksi penelitian ini. 